\title{
Erythromelalgic Symptoms in Left Subclavian Artery Stenosis
}

\author{
Takahiro Kametani, Yuichiro Otani, Keishi Kanno and Susumu Tazuma
}

Key words: erythromelalgia, subclavian artery stenosis

(Intern Med 59: 1235-1236, 2020)

(DOI: 10.2169/internalmedicine.4007-19)
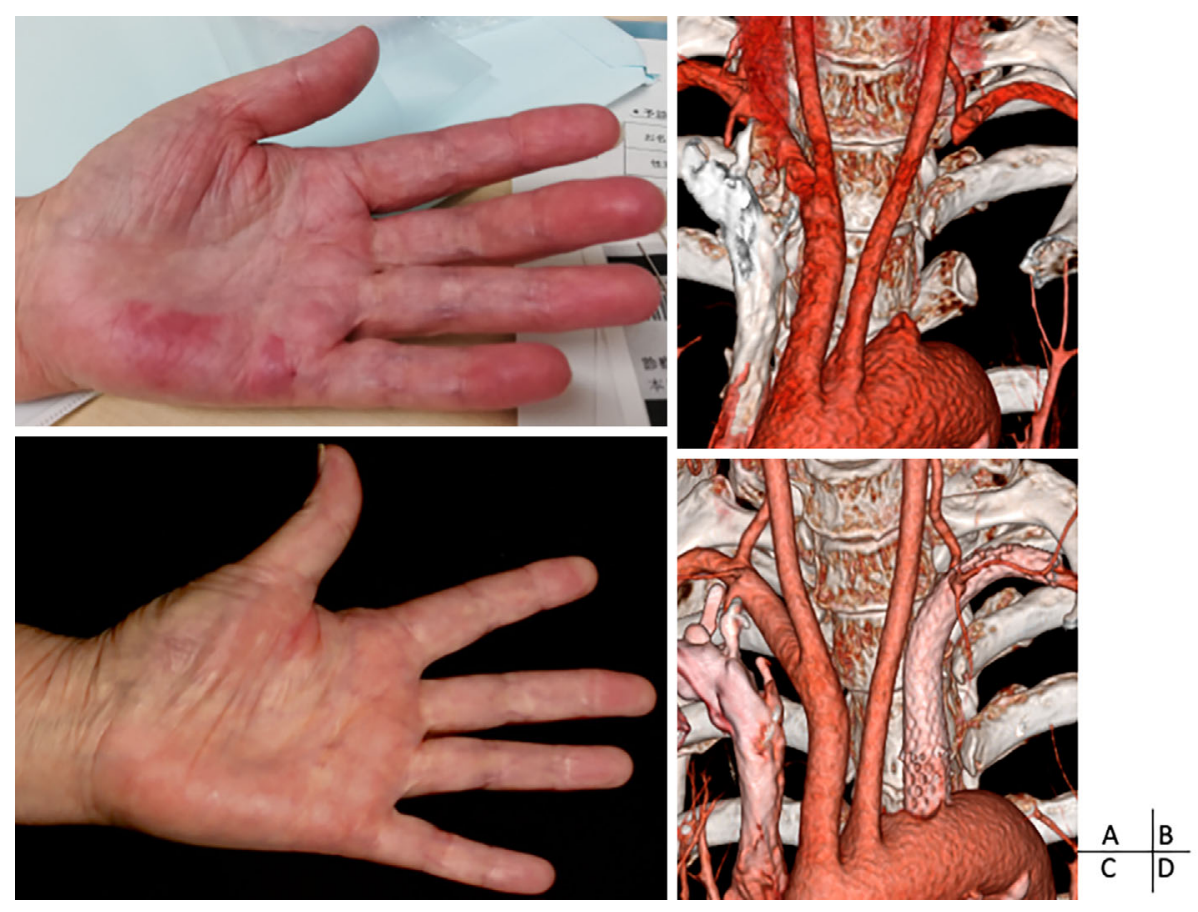

Picture.

A 70-year-old woman with hypertension and Sjögren's syndrome presented to the Department of Internal Medicine in mid-summer with a 2-year history of painful erythema in her left hand recurring only during summer (Picture A). She complained of burning pain that was relieved by cooling. The appearance of symptoms coincided with left subclavian artery stenosis (Picture B). On a physical examination, the blood pressures in her right and left upper arms were 136/83 and $116 / 83 \mathrm{mmHg}$, respectively. Notably, the left hand was warmer than the right. A laboratory examination revealed no evidence of myeloproliferative disease and a normal Ddimer level. Positron emission tomography revealed no evidence of large-vessel arteritis. Oral clopidogrel was initiated but was ineffective, and stenting of the subclavian artery was performed. Subsequently, all of her symptoms disappeared (Picture C, D).

The authors state that they have no Conflict of Interest (COI).

\section{References}

1. Thompson GH, Hahn G, Rang M. Erythromelalgia. Clin Orthop Relat Res 144: 249-254, 1979.

2. Mann N, King T, Murphy R. Review of primary and secondary erythromelalgia. Clin Exp Dermatol 44: 477-482, 2019.

The Internal Medicine is an Open Access journal distributed under the Creative

Department of General Internal Medicine, Hiroshima University Hospital, Japan

Received: October 4, 2019; Accepted: December 5, 2019; Advance Publication by J-STAGE: January 17, 2020

Correspondence to Dr. Yuichiro Otani, yuichiro-otani@hiroshima-u.ac.jp 
Commons Attribution-NonCommercial-NoDerivatives 4.0 International License. To view the details of this license, please visit (https://creativecommons.org/licenses/ by-nc-nd/4.0/)

(C) 2020 The Japanese Society of Internal Medicine Intern Med 59: 1235-1236, 2020 